\title{
Poder y violencia: el discurso visual del monumento a Cristóbal Colón (y la mujer indígena)
}

Recibido: 05/07/2021

Aprobado: 22/09/2021

\author{
DAVID A YALA DEL RÍO \\ Universidad Nacional Mayor de San Marcos (UNMSM) \\ Escuela Nacional Superior Autónoma de Bellas Artes \\ del Perú (ENSABAP) \\ david.ayala@unmsm.edu.pe \\ https://orcid.org/0000-0003-3247-8079
}

\begin{abstract}
RESUMEN
La gestión del patrimonio cultural se vuelve un campo de constante disputa en el cual los imaginarios colectivos toman un papel central. En este sentido, diversos elementos que componen nuestro panorama urbano comienzan a ser cuestionados, y es en este cuestionamiento que abordaremos el caso del monumento a Cristóbal Colón, desglosando los elementos simbólicos patriarcales y coloniales que alberga en su composición. Para ello, se realizará un análisis histórico de los procesos culturales y sociales que han llevado a la normalización de estos monumentos en el desarrollo de la república, así como la reacción generada en el consciente colectivo que ha desembocado en diversas acciones e iniciativas críticas. De esta forma, el artículo se propone entrar al debate reflexivo sobre el desarrollo de nuestra república en el marco del bicentenario y mostrar una necesaria gestión crítica de nuestros espacios públicos.
\end{abstract}

Palabras clave: patrimonio cultural, monumentos, símbolos coloniales, sexo-género

\section{Power and violence: the visual discourse of the Christopher Columbus monument (and the indigenous woman)}

\begin{abstract}
The management of cultural heritage becomes a contested field in which the collective imaginaries play a central role. Accordingly, different elements composing our urban landscape are being criticized and within this critique the case of the Christopher Columbus monument will be addressed, by breaking down the patriarchal and colonial symbolic elements of its composition. To this effect, an historical analysis of the social and cultural processes leading to the normalization of these monuments throughout the development of the republic, and the response in the collective consciousness that has led to different actions and critical initiatives. The article thus aims to open a reflective debate on the development of our republic in the face of the bicentennial and to draw attention on the necessary critical management of our public spaces.
\end{abstract}

Keywords: cultural heritage, monuments, colonial symbols, sex-gender 
La mujer proletaria consustancia su feminismo con la fe de las multitudes revolucionarias en la sociedad futura. La lucha de clases - hecho histórico y no aserción teórica - se refleja en el plano feminista.

J. C. Mariátegui ${ }^{1}$

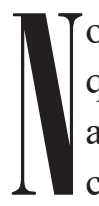
os encontramos en un escenario complejo, atravesamos una pandemia que ha golpeado duramente a diversos sectores de nuestra sociedad, situados en un país sumergido en una profunda crisis política, y a su vez cruzamos una fecha simbólicamente importante: el bicentenario de la independencia del Perú. Son diversos factores que le dan particularidad al tiempo que vivimos, pero que nos instan a evaluar y analizar nuestra sociedad críticamente. El conservadurismo, con enfoques machistas, misóginos y patriarcales, mantiene hegemonía en la mentalidad de diversos sectores de nuestro país y esto, a su vez, permite la reproducción de diversas violencias que se normalizan en la sociedad.

El bicentenario del Perú debe ser un punto de debate y reflexión sobre los avances y los retrocesos que se dan en miras a una amplia agenda que demandan los pueblos en sus diversos campos políticos, el campo feminista y el de las diversidades, los cuales comprenderán una base central en el análisis del presente artículo, así como los enfoques decoloniales y de clase. De este modo, nos situamos en un contexto que exige mayor atención sobre las mentalidades peligrosas que se mantienen en nuestra sociedad y que reproducen rezagos coloniales, patriarcales y racistas. Estos tienen «sus orígenes en un orden social, con patrones socioculturales sumamente arraigados, donde prima y se justifica la desigualdad de género en desmedro de las mujeres» (MIMP 2016).

Para comprender la forma en que se camuflan estos discursos en nuestra urbe, nos centraremos en un monumento que, bajo la nominación de ser patrimonio cultural de la nación, se mantiene intangible en nuestro espacio público, normalizando a su vez los roles de poder que representa: el monumento a Cristóbal Colón. Este simboliza la representación de lo europeo superior a lo originario, la negación estética de lo indígena bajo los cánones occidentales, la sumisión de la cultura originaria frente a la religiosidad judeocristiana, así como la pasividad humillante de la mujer indígena a los pies de Colón. Estos son elementos visuales que se mantienen normalizados en el ornamento urbano del centro histórico de Lima, y se convierten en bandera cultural de un gran sector conservador. Tal situación, según Segato $(2014,24)$, es a causa de que

1 Publicado en Variedades, Lima, 15 de marzo de 1924. 
«las independencias no deshicieron la colonialidad, [la cual] permaneció y se reprodujo como patrón para las formas de explotación del trabajo, configuración de las jerarquías sociales, administración política por los ahora Estados republicanos, y la subjetividad». Ahora resulta, en nuestro tiempo, un lastre que se resiste a desaparecer de las mentalidades de la sociedad.

La sociedad moderna, como consecuencia del largo yugo colonial, ha establecido patrones de poder que han desplazado las estructuras sociales tradicionales de los pueblos originarios. Esta consecuencia histórica del proceso colonizador es refrescada, de forma conmemorativa y heroica, por el monumento en mención, el cual muestra el victorioso colonizador en postura antagónica a la sumisa representación de los pueblos originarios a través de la mujer indígena. Este monumento nos muestra, pues, la violencia sistémica que recae sobre la mujer, aún más cuando es racializada en las sociedades americanas posterior al proceso de invasión y dominación española.

Este monumento, al vivir y convivir con el entorno social, y las percepciones contemporáneas, genera una reacción a su imposición. En este sentido, se han desatado diversas acciones que cuestionan su permanencia, perdiendo su intangibilidad ante la opinión social, instando a los mecanismos de diálogo, gestión y regulación una salida en respeto a la memoria crítica de nuestros pueblos originarios, así como lo ofensivo de la representación de poder sexista que figura en su composición. En este sentido, los imaginarios colectivos de la sociedad limeña no son estáticos, por el contrario, son dinámicos y cambiantes, según las lecturas y los consensos culturales que se establezcan. Esta dinamicidad de las percepciones y construcciones de identidad nos permiten hoy en día contemplar, cuestionar y proponer reformas necesarias en campos que antes no estaban politizados, como es el campo del patrimonio cultural, dentro del cual los monumentos que divulgan estos mensajes y simbolismos nocivos son enfrentados. Sin embargo, la reacción conservadora no es pasiva ante las nuevas lecturas políticas. De este modo, el monumento se convierte en un elemento central que polariza las percepciones culturales de la ciudad.

Esta ofensiva a los símbolos coloniales no es nueva: parte de una larga lucha por la reivindicación de lo no-occidental frente a lo occidental. Un escenario de crítica a estas estructuras socioculturales supremacistas y racistas se refleja en las luchas sociales del mundo actual. Las últimas luchas sociales desatadas en Estados Unidos, tras el asesinato de George Floyd por un policía blanco, es una de las luchas más visibles y mediáticas de los últimos años, ya que es un cuestionamiento al imperio desde sus entrañas. Junto con ello, en la 
región africana surge un cuestionamiento cultural y social a la invasión europea sobre sus territorios, como la belga y francesa; un efecto similar ocurre en la región latinoamericana frente a la invasión española. Imágenes como «los padres la patria» estadounidense que eran esclavistas, o el Rey Leopoldo II de Bélgica, o Cristóbal Colón, han perdido aquel velo de intangibilidad cultural, y toda representación pública de ellos ha sido escenario de protesta y acción.

Esta situación de disputa política es parte de una coyuntura que comienza a dar herramientas para cuestionar lo tradicionalmente aceptado, replanteando nuestros procesos históricos, los roles de sexo-género y la importancia de gestionar adecuadamente nuestros espacios públicos, y junto con ello el patrimonio cultural. Este conflicto nos exige tener la necesidad de aplicar enfoques adecuados en la gestión de estos campos, que cuestionen los sesgos tradicionales coloniales, racistas, discriminatorios, sexistas-machistas y burgueses. Lima y sus comunidades no son ajenas a las lecturas contemporáneas, así como la mutación en la percepción sobre los elementos que componen su paisaje urbano, tomando un papel activo en la crítica cultural. Estos cambios perceptivos se vuelven más notorios dentro de la dinámica social limeña, convirtiéndose los monumentos en cuerpos dialécticos que se muestran en constante cambio y acción política. Millán (2019) nos exhorta que «la cultura [...] es así un horizonte a deconstruir desde una perspectiva crítica y descolonizadora feminista». Con esa misma perspectiva, debemos juzgar y gestionar en el escenario patrimonial y en el espacio público.

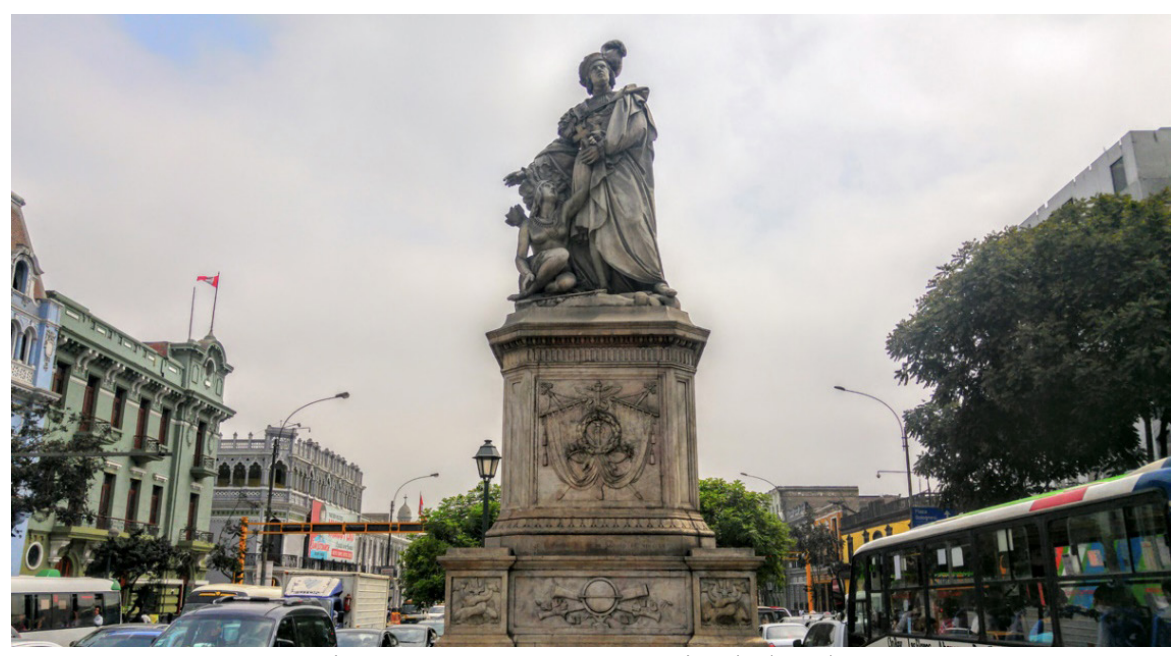

Figura 1. Monumento a Cristóbal Colón

Fuente: RPP (2017) 


\section{Un preocupante diagnóstico: la violencia de género como cultura}

Iniciamos el artículo con este importante análisis sobre la realidad social que vivimos, una donde la violencia por criterios de sexo-género son normalizadas, sumadas a rezagos coloniales que profundizan esta violencia. Como nos explica el Plan Nacional contra la Violencia de Género 2016-2021, «la violencia basada en género se cruza con las otras violencias (basadas en discriminaciones étnicas-raciales, por edad, por clase social, por discapacidad, por estatus migratorio, etc.), las ensombrece y complica, configurando así un sistema problemático complejo» (MIMP 2016).

En nuestra región, la etapa colonizadora ha implicado un profundo proceso violento de desarraigo en las comunidades originarias respecto a sus identidades históricas, forzando la adaptación de parámetros morales, religiosos y culturales de Occidente. Por ello, el rol de la mujer, de la «raza» y del estrato socioeconómico de los individuos tuvo un reordenamiento total. El patriarcado dejó de comprenderse de forma involuntaria y tradicional para ser parte de un sistema obligatorio en la nueva sociedad moderna.

Segato $(2016,213)$ apunta sobre este patriarcado sistémico en nuestra historia lo siguiente:

El patriarcado, o relación de género basada en la desigualdad, es la estructura política más arcaica y permanente de la humanidad. Esta estructura molda el funcionamiento de todas las desigualdades de prestigio y poder en todos los otros ámbitos de la vida; podríamos decir que se transpone en ellos. Las supremacías en los órdenes económico, político, colonial, racial son réplicas funcionales del orden patriarcal. Es por esto que nos encontramos todavía en el estacionario tiempo de la prehistoria patriarcal de la humanidad — tiempo histórico y no biológico, porque necesita de narrativas míticas y de preceptos morales para sustentarse.

El proceso de la colonia transfigura distintas formas de jerarquías sociales de las comunidades originarias, de lo tradicional a ser parte de un nuevo orden en el virreinato. La república, que fue un primer grito de libertad, no detuvo este orden opresor sobre los roles de género. Así como se romantizaba a las tapadas limeñas en el virreinato, por no denunciar la represión al libre tránsito de las mujeres, en la república veíamos lo mismo sobre el cómo debe ser una dama ante la nueva sociedad republicana, encasilladas a los roles que la colonia impuso, o el hecho de privarlas de la participación activa en los 
convulsionantes panoramas políticos de la naciente república. Segato (2016) seguiría explicando sobre este proceso histórico, señalando:

la jerarquía simple de un patriarcado de baja intensidad o bajo impacto en la vida comunal es intervenida por el proceso colonial, primero gerenciado por las metrópolis de ultramar y más tarde por los estados criollos republicanos. Es en este proceso y transición que la asimetría explícita y de baja intensidad de las comunidades pre-coloniales se transforma en un patriarcado de alta intensidad, en el que la vulnerabilidad de las mujeres es máxima.

El Perú, tras la invasión española y la imposición del virreinato, ha sido el bastión ideológico-cultural-social-económico del occidente ibérico. Incluso tras la frustrada revolución de José Gabriel Condorcanqui Noguera y Micaela Bastidas Puyucahua, junto con el miedo de los realistas ante el poderoso imaginario andino, profundiza la dogmatización de sus bases culturales en las comunidades, sobre todo la religiosa. En este sentido, no es casualidad que el Perú haya sido el último bastión de la corona española en la región. Esta férrea tradición ideológica ha calado en la mentalidad de generaciones, en las cuales se acepta y se normaliza los estratos sociales, diferenciaciones raciales, la discriminación y, claro está, la división por sexo-género. Esta estructura sociocultural que se refuerza en la colonia se mantiene en la república criolla y resiste ser desterrada en nuestra contemporaneidad. Tal mentalidad ha sabido sobrevivir en los sectores dominantes conservadores, tanto religiosos como políticos.

Estas violencias, a lo largo de la república criolla, han desarrollado diversos modos de acción. Según el Plan Nacional contra la Violencia de Género 2016-2021 (MIMP 2016), en nuestra sociedad podemos comprender la violencia de género en sus diversos tipos: física, psicológica, sexual y patrimonial/ económica. Estas violencias trazan un caótico lienzo sobre nuestra sociedad. Así vemos cómo, desde lo cultural, se gestan en los núcleos más íntimos de las mujeres. El Plan también nos detalla las modalidades de estas violencias, que se expresan en la violencia de pareja, el feminicidio, la trata de personas con fines sexuales, el acoso sexual, la violencia obstétrica, las esterilizaciones forzadas, el hostigamiento sexual, el acoso político, la violencia en conflictos sociales y armados, la violencia en los medios de información y comunicación, la violencia por la orientación sexual, así como las violencias contra las mujeres migrantes, las mujeres con VIH, las mujeres privadas de su libertad 
y las mujeres con discapacidad. Sin duda, los puntos que aborda este plan nos demuestran los grandes retos para lograr una sociedad justa e igualitaria en derechos.

Esta situación se ha visto agravada por el contexto de pandemia que cruzamos, en el cual los porcentajes de violencia han aumentado dentro del seno familiar e íntimos, demostrando que los peligros y violencias se dan en todo espacio. El 2020, tras ocho semanas de establecerse la cuarentena, se dio a conocer una terrible cifra: «12 feminicidios y 226 violaciones de las que 132 han sido a menores de edad. Todas ellas son víctimas a las que el aislamiento dejó confinadas y desprotegidas ante sus agresores» (Efeminista 2020). Esta alarmante situación nos exige abordar la problemática desde diversas disciplinas, donde diversos campos se ven relacionados y urgen ser atendidos.

Esta estructura patriarcal entra en cuestionamiento. En los últimos procesos sociales, los feminismos han abarcado gran relevancia en las luchas populares y en la igualdad de género. En este sentido, podemos ver en las luchas sociales de los últimos años gran protagonismo de las mujeres, comprendiendo una lucha transversal sobre la sociedad, como es la reivindicación de mujeres sindicalistas, defensoras del medio ambiente, dirigentes barriales, colectivas feministas, quienes articulan una amplia agenda antipatriarcal en los campos políticos, los cuales, incluso estando en oposición a la estructura política global, mantienen rezagos patriarcales y conservadores. Estos procesos de articulación, denuncia y acompañamiento se manifiestan dentro de las heterogeneidades de los espacios de organizaciones de las mujeres y de las diversidades, que coinciden en objetivos similares:

Al final, las feministas nos hemos esforzado a lo largo de la historia de nuestro movimiento por recrear sororidades, en el sentido de blindajes de los espacios nuestros, olvidando o quizás desconociendo que esos blindajes siempre han existido en el mundo comunal, hasta ser desalojados por la captura de toda asociación, representación y tarea de gestión en una esfera que ha totalizado la política y que se encuentra modelada «a imagen y semejanza» de las instituciones del mundo de los hombres. La historia de los hombres es audible, la historia de las mujeres ha sido cancelada, censurada y perdida en la transición del mundo-aldea a la colonial-modernidad (Segato 2016, 220)

Los procesos feministas contemporáneos se enfrentan a estas estructuras socioculturales que se enquistan en los campos religiosos, sociales y políticos. 
Una lucha que en la región latinoamericana va cobrando protagonismo y poder revolucionario.

Situándonos en una sociedad con terribles cifras y con actitudes nocivas normalizadas, como es Lima, los espacios públicos y los monumentos que alberga cumplen un papel instructivo y de representación social, lo cual los convierte en un espacio de disputa. De tal forma que los monumentos que albergan mensajes que refuerzan las mentalidades patriarcales y sexistas pierden el velo de intangibilidad, por más título academicista que se les agreguen, se vuelven vulnerables ante el imaginario colectivo. En este sentido el campo del patrimonio cultural, que por tradición era una espacio neutro y contemplativo, se convierte en un campo politizado y de acción constante.

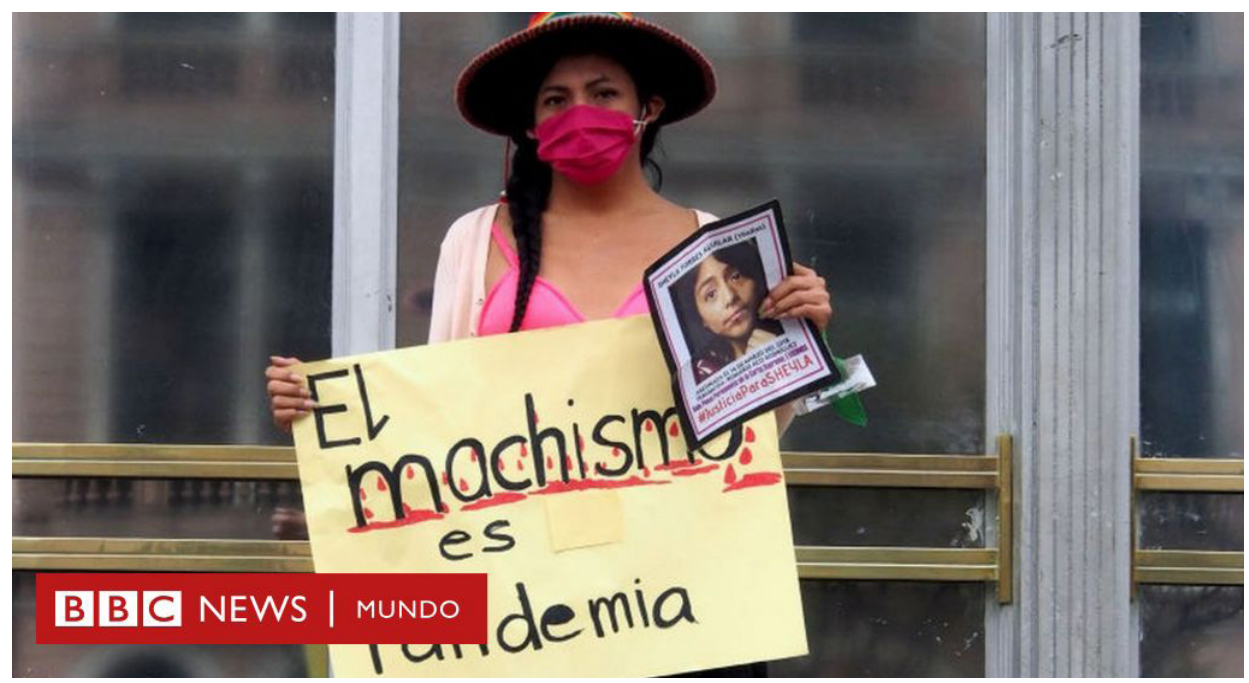

Figura 2. Violenta silente en el Perú

Fuente: BBC (2020)

\section{Violencia visual: roles de poder en el monumento a Cristóbal Colón}

Partiendo del análisis de la violencia patriarcal en nuestra sociedad, podemos comprender la importancia de cuestionar nuestros espacios públicos, los monumentos que albergan y el discurso visual que la urbe nos brinda. Al ser un espacio cotidiano y de tránsito constante, deben cumplir un rol central en la formación cultural y en el trato socializador de las personas. Lamentablemente, este punto de atención se encuentra lejos del interés de quienes gobiernan, gestionan y dirigen estos espacios. 
La estructura social de Occidente trajo consigo la opresión y delimitación a la libertad y dignidad de los pueblos originarios, de sus creencias, ciencia y culturas. Los poderes políticos y religiosos, en específico la Iglesia católica, impusieron modelos de virtud femenina, así como la persecución y destierro de las concepciones de valores femeninos positivos en las sociedades precolombinas, tomadas como disidencias o herejías, así como la legitimación de la violencia sexual durante el proceso de invasión. Esto marcaría el rumbo de la violencia de Occidente sobre la mujer en nuestra región.

Rita Segato $(2019,26)$, partiendo de un profundo análisis sobre Aníbal Quijano, nos explica que:

Podemos afirmar que el pivote del sistema se encontró en la racialización, la invención de raza, y la jerarquía colonial que se estableció y permitió a los «blancos» — más tarde llamados «europeos»— el control del trabajo [...]. De allí, esta jerarquía afecta los más diversos ámbitos de la experiencia, organizando siempre en forma desigual pares como precapital-capital, no europeo-europeo, primitivocivilizado, tradicional-moderno, etc.; como también Oriente-Occidente, primitivo-civilizado, mágico/mítico-científico, irracional-racional, tradicional-moderno. El referente de valor para esta jerarquía será siempre eurocentrado, resultante de un imaginario originado y siempre subliminalmente referido a la racialización de la mano de obra y a la reducción de las poblaciones no-blancas al trabajo servil o esclavo, solo hecho posible por la imposición de un orden colonial. Es por eso también, una vez más, que es el patrón colonial el que funda y organiza, hasta hoy, el camino del capital, y constituye su ambiente originario y permanente. El ideario hegemónico y eurocéntrico de lo «moderno» como paradigma, la «modernización» vista como un valor, lo «evolucionado»y lo «desarrollado», su instalación en el sentido común y en las metas de la ciencia y de la economía son también resultados de esa jerarquía fundacional, basada y construida sobre el cimiento de la raza y la racialización orientada a la explotación del trabajo.

Comprendemos, entonces, la base racial con la cual Occidente comienza a generar las diferencias sociales. Pero esta violencia racial no sería la única. Sobre esta violencia a cuerpos indígenas, afrodescendientes y externas a Occidente, también se enfoca la violencia a las culturas e identidades originarias y a los cuerpos femeninos. A esta alianza por mantener sumisos los pueblos originarios, y de la mujer en particular, se sumaron los poderes políticos criollos, la 
Iglesia católica y un conservador sector de la academia, quienes concebían los conocimientos de Occidente como los únicos reales.

No afectó solamente a las relaciones raciales de dominación, sino también a las más antiguas, las relaciones sexuales de dominación. En adelante, el lugar de las mujeres, muy en especial el de las mujeres de las razas inferiores, quedó estereotipado junto con el resto de los cuerpos, y tanto más inferiores fueran sus razas, tanto más cerca de la naturaleza o directamente, como en el caso de las esclavas negras, dentro de la naturaleza. Es probable, aunque la cuestión queda por indagar, que la idea de género se haya elaborado después del nuevo y radical dualismo como parte de la perspectiva cognitiva eurocentrista (Segato 2016, 31).

Esta estructura racial/económica/género fue reforzada por los imaginarios religiosos, culturales y simbólicos. Concretamente lo observamos en las apropiaciones de lugares de culto precolombinos, convertidos en recintos religiosos católicos, ya sean iglesias o monasterios. Así, encontramos la figura de Santiago Mata Moros (o indios) como representación triunfante de la fe católica sobre los herejes ajenos a Occidente; la cruz católica imponente sobre el apu del valle del Rímac, hoy denominado cerro San Cristóbal: o el famoso cuadro de los matrimonios de la ñusta Beatriz y de Lorenza de Loyola, que representa el fin de una casta y un triunfo simbólico de España sobre el incanato. ${ }^{2}$ La república no rompió con estos imaginarios occidentales, por el contrario, la mantuvo como forma de contener el orden sobre las comunidades indígenas, ante posibles insurgencias o protagonismos políticos en una recién nacida nación que les daba la espalda.

A puertas del bicentenario, es paradójico seguir romantizando los procesos violentos de nuestras historias y las connotaciones culturales que esto implica. Por ello, un análisis crítico sobre el espacio público, y sobre el monumento de Colón en específico, es necesario. Debemos comprender que, en el plano patrimonial, este monumento integra el patrimonio cultural de la nación, dada su antigüedad y el valor artístico de la obra. Su construcción fue planeada en el Gobierno de Rufino Echenique y realizada por el escultor italiano Salvatore

2 Nos referimos a la representación del matrimonio de Beatriz, la última ñusta del linaje de Vilcabamba, con Martín de Loyola, y el matrimonio de Lorenza de Loyola (hija del primer matrimonio) con el general Juan de Borja. Ante el objetivo de no generar descendencia entre las altas castas incaicas, no permitieron que se casen con caciques incas y las forzaron a contraer matrimonio con altos personajes españoles, perdiendo así su linaje. La ñusta Beatriz era hija de Sayri Tupac y sobrina de Túpac Amaru I; por su parte, Martín de Loyola, su esposo, fue el causante de la derrota de Vilcabamba. 
Ravelli, para ser presentada públicamente el 3 de agosto de 1860. Tuvo como primera sede el óvalo de la alameda de Acho, hasta 1872, cuando fue trasladado al sitio que actualmente conocemos como óvalo Grau; terminó por ser trasladado, por tercera y última vez, a la avenida 9 de Diciembre, lugar donde se sitúa hoy, adoptando el nombre de Paseo Colón. Irónica denominación para estar ubicado en una avenida que conmemoraba la última batalla que consolidó la independencia del Perú, así como ser la entrada al centro histórico de la capital peruana. En un artículo anterior, «Colonialidad y espacio público: el monumento a Cristóbal Colón en Lima» (2020), pude explicar esta problemática desde un enfoque histórico, apoyado en la teoría de la colonialidad del poder de Aníbal Quijano, para comprender la representación colonial y eurocéntrica que implica el monumento a Cristóbal Colón en nuestra capital y en nuestro tiempo. Un punto ligero abordado en el artículo fue el análisis de los roles de poder que reflejan los cuerpos de dicho monumento, omitiendo otro importante punto de cuestionamiento, que es la representación de poder según el sexo-género. En este punto del artículo, se profundizará este importante aspecto para tener una crítica más completa a dicho monumento.

Con la introducción a este título y un breve repaso histórico del monumento, podemos comprender que este responde a la esencial patriarcal y eurocentrista de la joven república, que a pesar de las guerras patrióticas añora y contempla su pasado colonial, manteniendo una visión occidental en su formación. En este sentido, podemos contemplar los roles de poder designados en el monumento.

Colón se muestra erguido, imponente, mirando al horizonte (señal de seguridad), vestido con ornamentos representativos de su época, acompañando sus ropas se puede apreciar la cruz católica y un medallón con los rostros de los reyes católicos. La imagen del hombre moderno, del descubridor, del instruido en la religión, en la ciencia y la tecnología, la representación de quien nos conectó con el mundo, occidental. Hasta allí, podemos describir al elemento central de la obra, pero no es el único cuerpo dentro de esta composición.

En contraste a esta forma de representación, se observa un cuerpo desnudo y sumiso a los pies del descubridor, mostrando admiración y gratitud. El segundo cuerpo corresponde a la representación de lo originario, del ser-naturaleza, la cual, bajo los criterios de Occidente, debe ser representada por una mujer. La representación indígena queda distante a las fisionomías locales, pues, incluso para representar la forma originaria, recurren a los cánones occidentales/renacentistas. La mujer indígena se muestra postrada a los pies de 
Colón, soltando su flecha en señal de rendición y con la otra mano recoge la cruz que le entrega el navegante. Ella se muestra desnuda, vulnerable y dócil frente al europeo. Como dice Vifian $(2015,106)$, «América está desnuda, mientras Colón viste sofisticadamente; y América está sentada, mientras Colón parado». A su vez, la mirada de la mujer indígena es contemplativa hacia Colón, el cual, por su lado, se muestra firme mirando al horizonte.

Esta subordinación estética no es casual, responde a criterios raciales, culturales y de sexo-género. Esta jerarquía de poder posiciona a la mujer como elemento pasivo y contemplativo en la obra, la musa que plantea Berger (1972). De esa forma se completa la composición central del monumento, donde se establece el orden jerárquico de lo occidental (Colón) y lo no occidental (mujer indígena), así como lo moderno y lo atrasado, el futuro y el pasado, el hombre y la mujer.

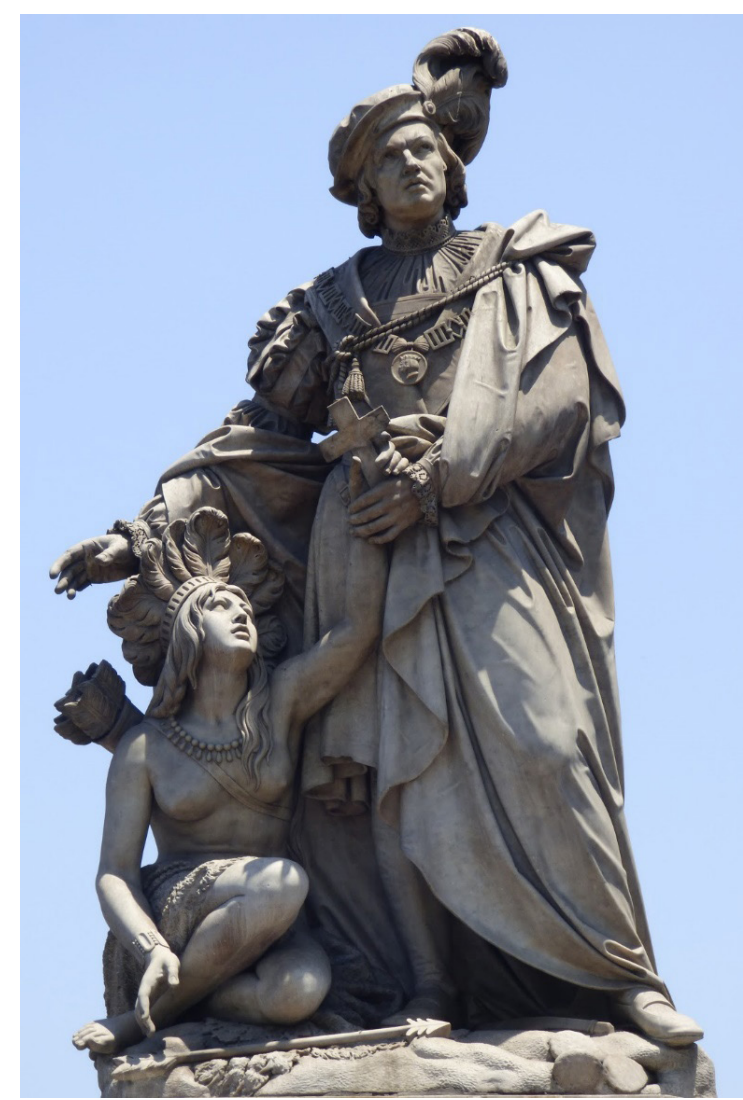

Figura 3. Monumento a Cristóbal Colón

Fuente: El hombre y su historia (2018) 
Un mensaje condenable que se impone a la entrada de la capital, siendo una herramienta que refuerza estos complejos desde el espacio público y desde la comodidad del patrimonio cultural. No en vano se vuelve símbolo de los sectores conservadores, quienes además de reproducir los pensamientos eurocéntricos, adjuntan también los pensamientos machistas y patriarcales.

Esta situación genera un ambiente de disputa, que cada 12 de octubre reabre los debates sobre la permanencia de este monumento. Las protestas han partido desde pintas sobre la estructura, denominadas como «atentados» por los sectores conservacionistas, como lo hizo en su tiempo Vladimir Velásquez desde su portal Lima Antigua el 2016. En contraste, Espejo $(2016,8)$ explica que «las pintas son realmente manchas que hacen alusión a la violencia que todo el proceso de colonización trajo consigo, para que, finalmente, se impongan la corona española en estas tierras». Otras protestas se han sumado desde diversas herramientas visuales y culturales, entre ellas las marchas y plantones. Los últimos años no solo la crítica decolonial se ha mostrado en este reclamo, también los discursos feministas y clasistas (desde la identidad proletaria) contra la permanencia del monumento a Colón.

\section{Una protesta necesaria: cuestionamiento y re-significación de los monumentos}

Los monumentos han perdido la intangibilidad ante la opinión colectiva, esto los convierte en objetos de intervención simbólica. La carga opresora, racista y sexista se vuelven punto de conflicto en el ambiente urbano. Vega (2016, 219) nos explica la situación con la que se le trata a la mujer en el espacio público:

[...] los espacios públicos urbanos, los parques y rotondas se han llenado otra vez de cuerpos de mujeres parcial o totalmente desnudos, como si las imágenes de cuerpos femeninos incorporasen ya belleza por sí mismas, mejorando, con su mera presencia, la calidad del espacio público; del mismo modo que el cuerpo de una joven embellece y ennoblece el acto o el lugar en que aparece, se trate de una entrega de trofeos a un héroe.

Como hemos visto, el monumento a Cristóbal Colón reafirma una ideología nociva en nuestra sociedad. La representación de la mujer indígena ha sido 
deformada en el monumento, se la reconstruye ajena a su canon natural, se la inferioriza, se la humilla, se la desnuda a los pies del hombre, de Occidente, del sistema. Frente a esta situación, las lecturas contemporáneas vienen cuestionando, enfrentando y revolucionando en el campo patrimonial.

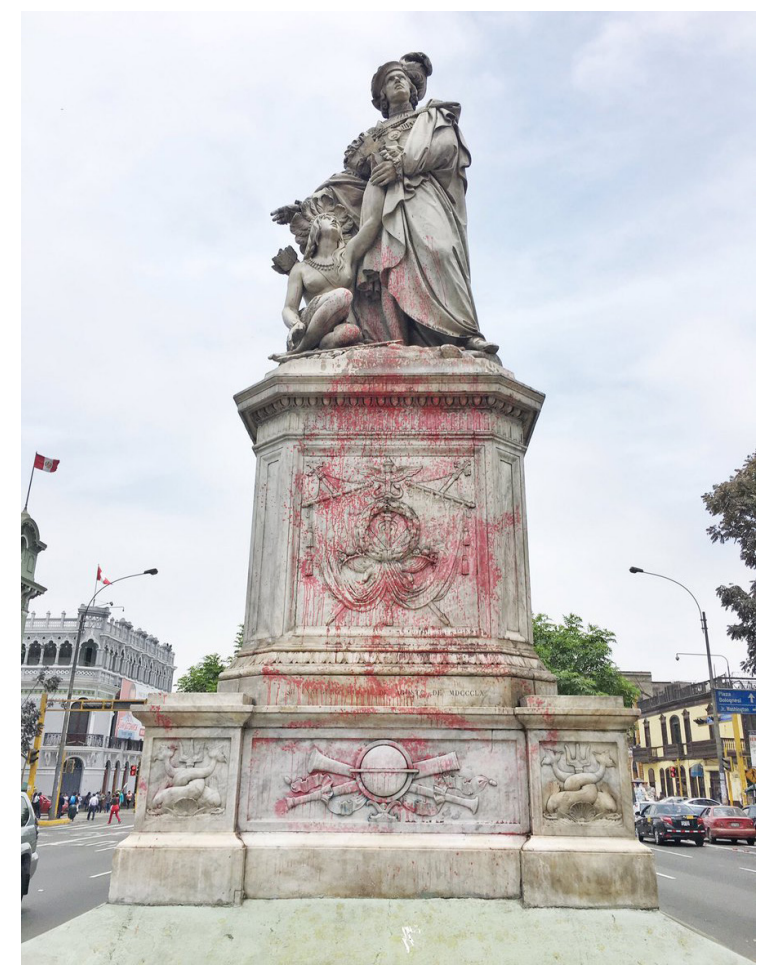

Figura 4. Protesta en el monumento a Colón

Fuente: Lima La Antigua (2016)

Domínguez (2020) explica sobre las reacciones radicales de los grupos feministas contra monumentos y elementos patriarcales, racistas y coloniales que representan el orden colonial en el espacio público: «esto habla de una serie de ira contenida, de furia e impotencia que venimos cargando las mujeres». En México, grupos feministas y familiares de víctimas de violencia tomaron el edificio de la sede de la Comisión Nacional de Derechos Humanos (CNDH) el 4 de septiembre del 2020, como reacción a la tibia objetividad para abordar los problemas de violencia de género que sufren las mujeres en México; junto con ello, ocurrió una oleada de protesta en la cual los patrimonios fueron lienzos para los mensajes políticos. El 12 de octubre del 2020, en 
La Paz (Bolivia), colectivos feministas, entre ellas Mujeres Creando, intervinieron y se apropiaron del monumento a la reina Isabel de España, o Isabel La Católica, vistiéndola de ropas culturales de las comunidades bolivianas: pollera, sombreros, colores y simbología altiplánica boliviana, rebautizando la plaza con el título de «Plaza Chola Globalizada». Aunque estas acciones caen en lo efímero y momentáneo de las intervenciones de arte contemporáneo, su valor simbólico genera un gran precedente que rompe la intangibilidad que se atribuye a los elementos patrimoniales, mostrando lo válido de resignificar estos símbolos según la conciencia colectiva del pueblo lo determine. Esta combinación poderosa de arte contemporáneo y activismo político sobre los monumentos públicos nos demuestra que «las prácticas artísticas cumplen una función en la constitución y el mantenimiento de un orden simbólico dado, o en su desafío, y es por esto que tienen necesariamente una dimensión política» (Mouffe 2014).

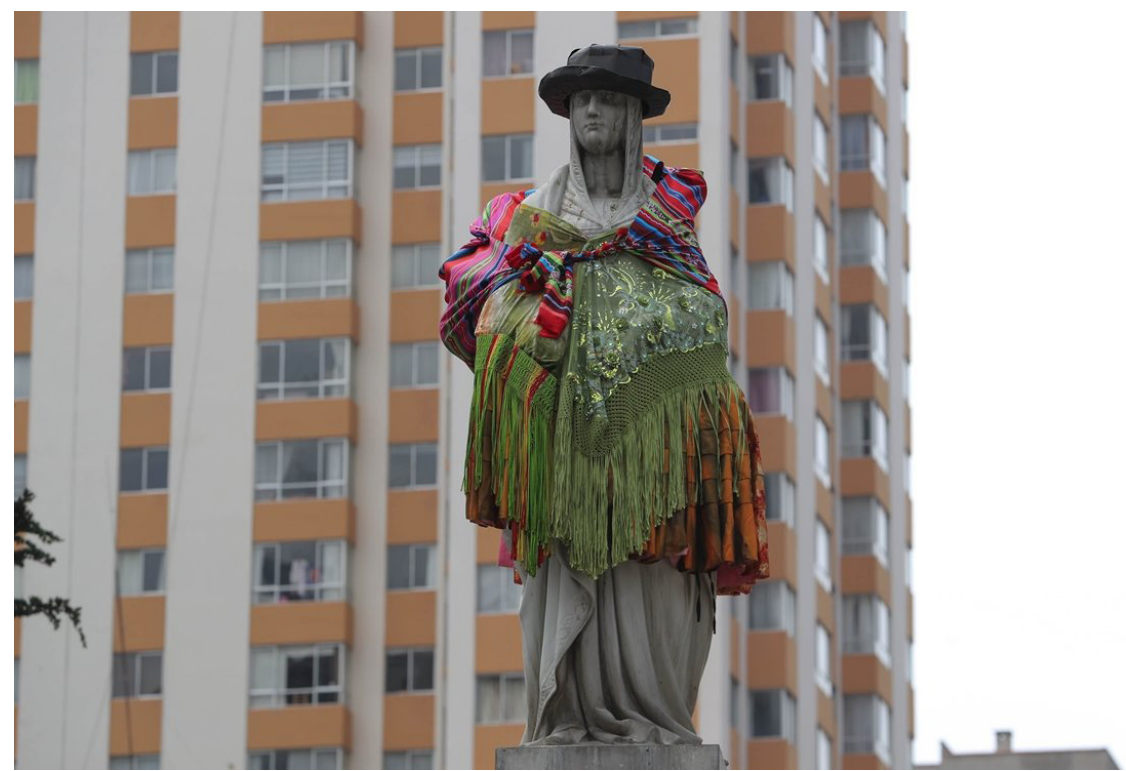

Figura 5. Plaza Chola Globalizada

Fuente: Radio Fueguina (2020)

En Chile, el 2 de marzo del 2020, el grupo Feminista 8M, entre sus diversas acciones colectivas previas al Día Internacional de la Mujer Trabajadora, realizó una intervención sobre los monumentos públicos, renombrando a los autores por el de mujeres artistas de diversas épocas. De esta manera, cuestio- 
naban la cobertura mediática que se da al arte de autoría masculina, algo normalizado en la academia patriarcal artística, lo cual mantiene en una constante invisibilización a la mujer artista-creadora. En Ecuador, en la madrugada del 20 de septiembre del 2019, colectivos y activistas feministas intervinieron estatuas y monumentos del centro histórico de Quito, colocando pañuelos verdes, así como pintas con frases como «¡Aborto ya!» y «Son niñas, no madres». Esta protesta fue en el marco de la decisión del Parlamento de rechazar la despenalización del aborto para las víctimas de violación. Occidente, tras el asesinato del ciudadano afrodescendiente George Floyd, volvió a emerger el cuestionamiento a los imaginarios supremacistas que se habían mimetizado con la cultura oficial; en este sentido, el derribo de estatuas y monumentos que representaban a presidentes esclavistas, como en Estados Unidos, o reyes genocidas, como el de Leopoldo II de Bélgica, se acrecentaron. Este año, continúan las protestas eufóricas contra estos simbolismos: en Canadá, tras descubrirse el genocidio de niños indígenas y romperse el imaginario del Occidente pacifista y armonioso, se iniciaron una serie de protestas contra los símbolos católicos y de dominación sobre los pueblos originarios de la región. Al sur, en Colombia, dentro de una amplia agenda de lucha de los pueblos, el enfoque decolonial está presente, como se demostró el 28 de junio en el derribo de la estatua a Cristóbal Colón en Barranquilla, bajo el grito de «¡Colón asesino!».

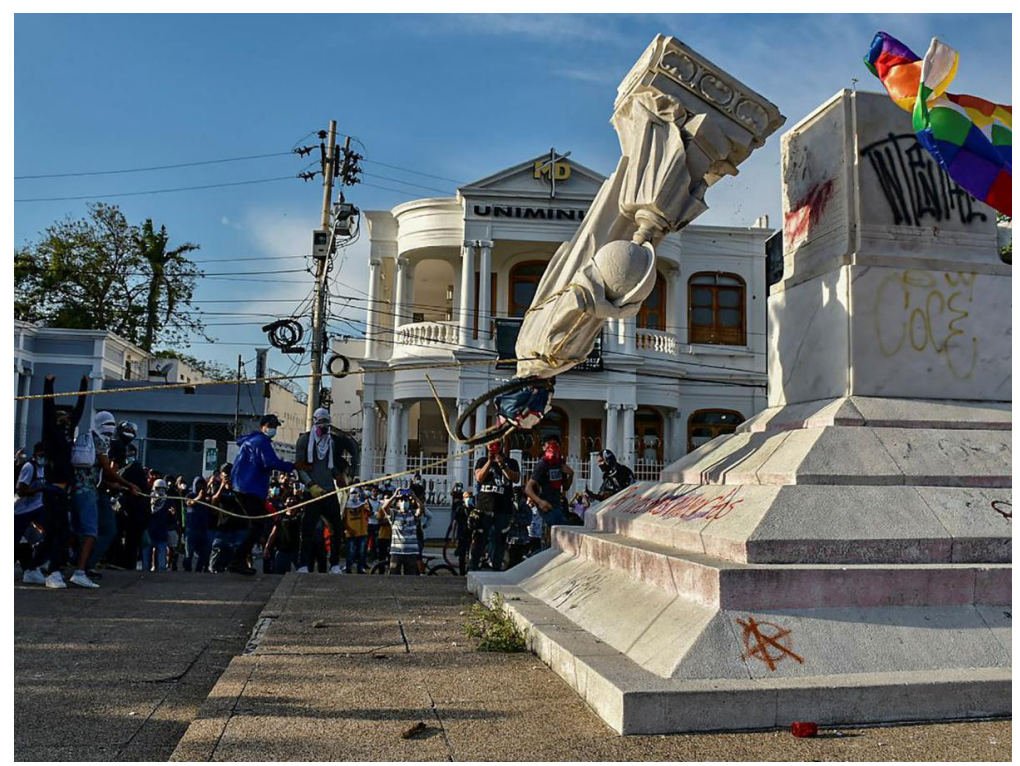

Figura 6. Derribo de la estatua de Cristóbal Colón

Fuente: El Comercio (2021). 
Perú no es ajeno a este escenario de reacción. En 1953 y en el 2003, en Lima, se llevaron a cabo dos reubicaciones al monumento ecuestre de Francisco Pizarro, el cual fue escenario de constante crítica, por ser la imagen de quien llevó a cabo una de las campañas más ambiciosas y sangrientas de España en la región. El debate originado por este monumento culminó en la reubicación definitiva en el parque de la Muralla, en la cual se mantiene ajeno al panorama urbano que por mucho lo albergó. Nuestra contemporaneidad no solo eleva criterios formales de lucha, también emprende acciones de protestas; de esta forma, podemos observar grupos feministas, anti-racistas y anti-coloniales que han generado críticas e intervenciones en espacios patrimoniales, sobre monumentos arquitectónicos o escultóricos. Podemos ver intervenciones significativas que han encontrado escenario en los espacios patrimoniales del centro histórico de Lima, como «Alfombra roja», la cual denuncia las injusticias y trabas del Poder Judicial dentro de las demandas feministas; «Nosotras estamos en la calle», propuesta artística gestionada por la socióloga y artista visual Mónica Miros, el cual ha intervenido en espacios barriales y patrimoniales en el Cercado de Lima con temáticas feministas. Además, otras intervenciones relacionadas al 8 de marzo, Día Internacional de la Mujer, y el 25 de noviembre, Día Internacional de la Eliminación de la Violencia contra la Mujer, así como la lucha por la legalización del aborto.

El monumento en cuestión no ha sido ajeno a estas reacciones. El 12 de octubre se vuelve una fecha de reflexión y análisis crítico sobre nuestra historia y los rezagos que perduran en nuestros días, que se han mimetizado con elementos nocivos del sistema imperante. El 2015 y el 2016 se realizaron pintas sobre el monumento en protesta por la simbología colonizadora que mantiene; el 2020, a pesar de la pandemia, nuestro país no fue ajeno a las acciones de reflexión sobre el monumento y el espacio público, así como la reacción global que se manifestó contra los monumentos que representaban a Cristóbal Colón, personajes de la colonia y esclavistas. En Lima se gestaron iniciativas colectivas y se realizaron plantones criticando el orden colonial que significa este monumento, así como el mensaje misógino en su composición.

En este sentido, el campo del patrimonio cultural ya no es un escenario pasivo. Mientras nuevas lecturas críticas crecen en la colectividad, una nueva gestión del patrimonio cultural se va forjando con enfoques necesarios para el bien social. 


\section{A modo de conclusión: una gestión crítica del patrimonio cultural}

En nuestro tiempo, muchos conceptos dejan de lado su esencia tradicional y se vuelven elementos adaptables a nuevas lecturas y dinámicas contemporáneas, siendo la sociedad en sí un espacio continuamente mutable. En esta premisa, abarcamos esta contemporaneidad sobre el concepto de patrimonio cultural en nuestra realidad/tiempo. Según Choay (2007), este concepto se encuentra en constante transformación y trayectoria: ha pasado de ser un elemento contemplativo e intangible, a ser una creación colectiva que representa identidad y que se readapta a nuestras lecturas. Debemos señalar que el patrimonio cultural representa un espacio de convivencia donde cada individuo se reafirma al sentirse parte de un grupo con el cual se identifica, y sentirse parte en la construcción de una memoria colectiva y sus significados. Es aquí donde podemos apreciar que el patrimonio se convierte en un lugar de complicidad social, en el cual se expresa la solidaridad que une a quienes comparten los mismos valores culturales (García Canclini 1987). En un escenario como el bicentenario de nuestra independencia, estos espacios de convivencia y de reafirmación cultural deben ser reforzados, comprendidos y gestionados adecuadamente.

El bicentenario de la independencia del Perú implica una fecha para replantear cómo hemos avanzado y qué estamos construyendo como país; en ese escenario, el campo cultural-patrimonial tiene gran importancia. Sin embargo, partiendo de este panorama, aún afrontamos los sesgos patriarcales, racistas y eurocéntricos de la colonia, y, por otro lado, cruzamos un panorama que nos exige integración frente a una pandemia que trae consigo una crisis social y política. En esta situación conflictiva y polarizada debemos comprender el papel central de nuestro patrimonio cultural como un campo que nos conecta con nuestro entorno, historia e identidad.

Dentro del campo patrimonial surgen nuevas propuestas para gestionar con enfoques necesarios y críticos a favor de la colectividad. Nuevas generaciones de gestores con enfoques interdisciplinarios pueden generar esa revolución necesaria en nuestro tiempo, y en beneficio de la sociedad en general. Los velos tradicionales del patrimonio entran en cuestión, la intangibilidad simbólica del patrimonio pierde vigencia ante la conciencia colectiva. Comprendemos de esta forma que el patrimonio es un elemento que vive y convive con su entorno social, y se transmuta según el pensamiento colectivo y resignifica sus elementos ante lecturas contemporáneas. 
Este escenario de disputa ha evidenciado una polarización sobre la gestión del patrimonio cultural y del espacio público; respuestas críticas decoloniales, anti-racistas, feministas y anti-clasistas se han manifestado, pero también se han evidenciado las reacciones conservadoras y patriarcales. En este sentido, los grupos patrimoniales reforzados por las instituciones que rigen sobre ellas se resisten a cambiar sus enfoques, desde PROLIMA, como entidad encargada de la Municipalidad Metropolitana de Lima sobre el centro histórico, y el Ministerio de Cultura, los cuales aún muestran resistencia ante los enfoques contemporáneos. Lo mismo ocurre con la Comisión de Cultura del Congreso, en la que se encuentran defensores de los grupos de poder conservadores que llegan al Legislativo, y muestran una oposición a los nuevos enfoques, necesarios en nuestra sociedad. Esta resistencia al cambio permite que las protestas sigan creciendo, forzando el debate sobre estos monumentos. Por otro lado, su recia oposición también se escuda de los discursos patrimonialistas de entidades internacionales, sin embargo, termina siendo una visión sesgada y atemporal que no comprende los debates contemporáneos que se están dando dentro de estos organismos. La UNESCO $(2015,8)$, en la Convención de Género y Patrimonio Cultura, explica que, «como las relaciones de género de las comunidades están en constante evolución, ello posibilita el avance hacia una igualdad de género y la superación de la discriminación a este respecto a través de la práctica del patrimonio cultural». Ahí recae el valor de la gestión del patrimonio cultural según las exigencias de nuestra realidad.

En términos de Zúñiga (2017), lo central en la gestión patrimonial en el campo de la cultura es la memoria, la cual no solo se debe enfocar en el estudio de la historia, como elemento universal, siendo una representación del pasado y sobre nuestro desarrollo histórico y social; la memoria más debe referir un proceso actual, emotivo y afectivo que surge de desde un grupo social, y que se encuentra en relación permanente entre el recuerdo y el olvido. La historia se manifiesta en acontecimientos de carácter objetivo, mientras que la memoria se aferra a lugares, y no constituye un elemento único, sino que existen diversas memorias que son a la vez individuales y colectivas (Nora 2009). En este sentido, y en nuestro tiempo, debemos agregar nuevos significados e interpretaciones sobre nuestro pasado y su patrimonio cultural, comprendiendo adecuadamente nuestro desarrollo histórico con lecturas contemporáneas que permitan formular una memoria que fortalezca nuestra identidad. De esta forma, se rompe con el romanticismo que cae sobre el proceso de invasión, de imposición de Occidente sobre las tierras, así como la 
imposición de una gran estructura patriarcal, heredada hasta nuestros tiempos. Reafirmar el compromiso en esta lucha frontal contra los rezagos coloniales en la gestión patrimonial de la cultura es un deber.

Quienes trabajamos dentro de la gestión del patrimonio cultural debemos comprender que es necesaria la politización de este campo y reforzar sus lazos con las comunidades en las que vive y convive. La gestión vertical y elitista, que ha primado en el campo patrimonial, lo ha mantenido al margen de las dinámicas sociales, retrayendo este campo al lado más conservador y reaccionario de la cultura institucional. 


\section{Referencias bibliográficas}

Ayala, D. 2020. Colonialidad y espacio público: el caso del monumento a Cristóbal Colón en Lima. Revista Nueva Hegemonía, (2). https://bit.ly/3xKGX1k

Berger, J. 2013. Modos de ver: La mujer en el arte (video). Bonete 333. https://www. youtube.com/watch?v=MDcyd_9Y9Yc

Choay, F. 2007. Alegoría del patrimonio. Barcelona: Editorial Gustavo Gili.

Domínguez, O. 2020. Iconoclasia: ¿por qué las mujeres rompen y queman todo? Heraldo de México. https://bit.ly/3rhdhXn

Espejo, A. 2014. El caso de las pintas al monumento de Cristóbal Colón en Lima. Issuu. com (DesHecho Urbano). https://bit.ly/2UYRuHy

García Canclini, N. 1987. ¿Quiénes usan el patrimonio? Políticas culturales y participación social. Boletín Oficial del Instituto Nacional de Antropología e Historia, (15), 11-24. Ciudad de México.

Gimeno, F. 2020. Las otras cifras de la COVID en Perú: 12 feminicidios y 226 violaciones. Efeminista. https://bit.ly/2UsxhKm

Millán, M. 2019. Genealogías descolonizantes en los feminismos emergentes: el impacto de las mujeres zapatistas. Revista Punto Negro, (11), 18-32.

Mouffe, C. 2014. Agonística. Pensar el mundo políticamente. Buenos Aires: Fondo de Cultura Económica.

Nora, P. 2009. Lugar conmemorativo. Santiago de Chile: LOM.

Ministerio de la Mujer y Poblaciones Vulnerables (MIMP). 2016. Plan Nacional Contra la Violencia de Género 2016-2021. Lima: autor.

Segato, R. 2016. La guerra contra las mujeres. Buenos Aires: Editorial Prometeo.

Segato, R. 2019. La perspectiva de la colonialidad del poder. En Z. Palermo y P. Quintero (Comps.). Aníbal Quijano, textos de fundación. Buenos Aires: Ediciones del Signo.

UNESCO. 2015. Convención sobre el patrimonio cultural inmaterial y género. París: autor. https://ich.unesco.org/doc/src/34300-ES.pdf

Vega, E. 2016. ¿Una violencia invisible? Las mujeres en los monumentos públicos. Boletín de Arte, (37), 213-225, Málaga.

Vifian, D. 2015. Estatua conmemorativa a Cristóbal Colón (1851-1860): ciencia y religión, hermanas civilizadoras. Revista de Estudios Interdisciplinarios de Arte y Cultura, 2(1), 75-117.

Zúñiga, P. 2017. Patrimonio y memoria: una relación en el tiempo. Revista de Historia y Geografía, (36), 189-194. 